\title{
Dyslipidemia in HIV-1 Infected Subjects with Short Term Usage of Highly Active Antiretroviral Therapy (HAART) in Benin City, Nigeria
}

\author{
${ }^{1 *}$ O. G. Igharo, ${ }^{2}$ T. L. Olawoye, ${ }^{1}$ H.B. Osadolor, ${ }^{1}$ F. A. Idomeh, ${ }^{1}$ O. J. Osunbor, ${ }^{3}$ A. O. Osagie and \\ ${ }^{4}$ O.C. Iyamu \\ 1Department of Medical Laboratory Science, School of Basic Medical Sciences, University of Benin, Benin, Nigeria \\ 2Department of Biochemistry, Federal University of Technology, Akure, Nigeria. \\ 3Department of Medical Biochemistry, School of Basic Medical Sciences, College of Medical Sciences, University of Benin, \\ Benin City, Nigeria. \\ ${ }^{4}$ Department of Physiology, School of Basic Medical Sciences, College of Medical Sciences, University of Benin, Benin City, \\ Nigeria \\ [Corresponding author: e-mail:osaretin.igharo@uniben.edu; $\mathbf{P}:+2348038664896]$
}

\section{ABSTRACT}

This study aimed to investigate the short-term effects of Highly Active Antiretroviral Therapy (HAART) (stavudine, lamivudine and nevirapine) on serum lipids of HIV-1 positive subjects in Benin City, Nigeria. Test group $1(n=78)$ and test group $2(n=71)$ comprised HIV- 1 seropositive individuals on HAART for a period of one to three months; and five to six months respectively. Fifty five newly diagnosed HIV-1 positive subjects naïve to HAART served as control group 1 and sixty apparently healthy HIV-1 seronegative individuals served as control group 2. The blood samples obtained were analyzed for total cholesterol, triglycerides, low-density lipoprotein and high-density lipoprotein using standard enzymatic methods. Total cholesterol of test group $2(214.0 \pm 6.43 \mathrm{mg} / \mathrm{dL})$ was not significantly different from Test group $1(202.4 \pm 5.09 \mathrm{mg} / \mathrm{dL})$, both were however significantly higher than control group 1 $(159.3 \pm 5.09 \mathrm{mg} / \mathrm{dL})$ and control group $2(101.6 \pm 3.76 \mathrm{mg} / \mathrm{dL})$. Triglyceride concentration of test group 2 $(106.6+11.95 \mathrm{mg} / \mathrm{dL})$ was not significantly different from test group $1(135.8+9.88 \mathrm{mg} / \mathrm{dL})$, but were significantly different from control groups 1 and $2(125.1+3.35 \mathrm{mg} / \mathrm{dL}$ and $104.6+3.08 \mathrm{mg} / \mathrm{dL})$ respectively. Dyslipidemia could set in from 1 to 6 months of HAART usage in HIV-1 Positive subjects hence serum lipids should be monitored as early as one month of HAART commencement.

Keywords: Dyslipidemia, HIV chemotherapy (HAART), Lipid profile, HIV

\section{INTRODUCTION}

One of the reasonable goals for HIV chemotherapy (HAART) is to get the most effective drugs with minimal or negligible side effects in the long run. However, the long term survival of the treated patients have revealed several metabolic complications such as lipodystrophy, bone mineral depletion, liver failure, lactic acidosis, among others. Elevated serum triglycerides, total cholesterol, very low density lipoprotein (VLDL) cholesterol, and low density lipoprotein (LDL) cholesterol have been reported in the literature from areas where experience with antiretroviral drugs has built up. It was reported in the study conducted by Kubeyinje and Imarhiagbe (2005) that three cases out of eleven followed up on antiretroviral drugs for a period of 6 months had a steady rise in serum triglyceride level, among other parameters.
Until recently, the use of antiretroviral drugs in Nigeria on a wide scale was a rarity owing largely to prohibitive cost, and so experience with its use was limited. HAARTs are now highly subsidized or in some cases free in Nigeria. Study of this nature is important among different indigenous populations and communities, to help ascertain effects of these agents on lipid metabolism and on the liver as an important metabolic organ (Aggarwal et al., 1996).

Therefore, understanding the establishment and progress of HAART induced toxicity with short term usage by HIV-1 subjects in Nigeria would be of important research interest. Highly Active Antiretroviral Therapy (HAART) is composed of multiple antiretroviral drugs, which usually includes one nucleoside analog (Deoxyribonucleic Acid chain terminator), one protease inhibitor and either a second 
nucleoside analog or a non-nucleoside reverse transcription inhibitor (NNRTT) (Aggarwal et al., 1996; Aggarwal and Olivero, 1997).

Several advances have been made in the management and treatment of HIVIAIDS infection. Of particular note is the use of HAART, which has significantly decreased the morbidity and mortality caused by the infection (Stacpoole, 1993; Smit et al., 2003; Kubeyinje and Imarhiagbe, 2005; Pol et al., 2011). However, the long term survival of the treated patients have revealed several metabolic complications such as lipodystrophy (condition resulting in loss of fat tissues from part or all of the body), bone mineral depletion, liver failure, lactic acidosis, among others (Aggarwal et al., 1996). Also, among a cohort of seventy four (74) HIV positive persons treated with HAART, there was evidence of Lipodystrophy (Aggarwal and Olivero, 1997. Elevated serum triglycerides, total cholesterol, very low-density lipoprotein (VLDL) cholesterol, and low-density lipoprotein (LDL) cholesterol have been reported in the literature from areas involved in therapeutic trials (Aggarwal et al., 1996; Aggarwal and Olivero, 1997).

Based on cultural and environmental differences, the situation (HAART and its effects) in our local environments needs to be known in greater dimensions, and then compared with data and findings from foreign studies. This is very important especially for the HIV positive Nigerians who have shown serious compliance with the antiretroviral therapies. Beside the aim of establishing the long and short term effects of HAART on liver enzymes, this study also seeks to direct research attention on how to solve the problems of effects the drugs in order to minimize their side effects for the betterment of people living with HIVIAIDS in Nigeria, who of course still have full right to life.

\section{MATERIALS AND METHODS}

The Subjects (Test Groups)

Two Test Groups were used: Test Group One and Test Group Two.

Test Group One: HIV-1 Positive Individuals on HAART for 1-3 Months A total of seventy eight
(78) blood samples from HIV-1 positive patients (49 females and 29 males) who were on HAART for a duration of 1-3 months were analyzed for serum lipids: total cholesterol, triglycerides, low density lipoproteins (LDL), and high density lipoproteins (HDL).

Test Group Two: HIV-1 Positive Individuals on HAART for 5-6 Months A total of seventy one (71) blood samples from HIV-1 positive patients (30 males and 41 females) who were on HAART for a duration of $5-6$ months were analyzed for Serum lipids: total cholesterol, triglycerides, low density lipoproteins (LDL), and high density lipoproteins(HDL).

\section{Permission for Sample Collection/Inclusion Criteria}

The above groups of patients were known HIV1 sero-positive patients attending a Government owned health facility in Edo State for routine laboratory testing and for assess to antiretroviral therapies. Care was taken to ensure that patients reasonably complying with drug usage were selected for the work. Approval of ethical committee with permission to obtain samples was sought and obtained from the head of the laboratory department on behalf of hospital management. All samples were obtained in line with the Ethical Principles for Medical Research Involving Human Subjects by World Medical Association Declaration, Helsinki, 1994 and 2000.

\section{The Control Groups}

Two control groups were used: Control group one and Control group two.

Control Group One: A total of fifty (50) blood samples were obtained from individuals newly diagnosed of HIV-1 (both first timers and those already attending counseling sessions before commencement of antiretroviral therapies). Subjects of this group were apparently healthy and were, for one reason or the other attending clinic in a missionary hospital and the aforementioned source, both in Benin City. They were however, screened using Determine HIV $1 / 2$ diagnostic strips; and the results showed positive. 
Control Group Two: A total of sixty one (61) samples were obtained from apparently healthy volunteers chosen from random population. They included friends, co-workers, students, and fuel attendants. They were screened using Determine Test Kits and only the HIV seronegative subjects were included in the research work. In all the control subjects, liver enzymes activities and lipid profile were equally determined.

The Antiretroviral Drugs: Three different antiretroviral drugs made up of Nucleoside Reverse Transcriptase Inhibitors (stavudine/lamivudine) and Non-nucleoside Reverse Transcriptase Inhibitors (Nevirapine) constituted the HAART administered to the test group individuals in the centre where samples were obtained.

Sample Collection and Storage: Venous blood samples were obtained in plain (anticoagulant-free) specimen bottles using acceptable phlebotomy techniques.

The blood samples were allowed to clot, centrifuged at 3000 revolution per minute for 3 minutes, sera were collected and analysed immediately for the research parameters. Where this was not possible, the samples were stored frozen until required. Frozen samples were thawed and brought to room temperature before being analysed. All samples for the different groups were properly labeled to avoid mix-up and were handled using safety gloves and protective lab clothing. The samples were immediately discarded for incineration after analysis. Sodium hypochlorite (10\%) solution was used to disinfect working areas after analysis. It was ensured that all handling and analysis of samples took place in approved working areas only.

\section{Estimation of Serum Lipid Profile}

The lipid profile analysis of the samples was done using standard biochemical spectrophotometric methods.

\section{Data Analysis}

The single factor ANOVA both parametric and non-parametric was used to determine significant differences in the enzyme activities and lipid levels in the two durations of HAART usage and in the two control groups. Where a significant difference $(P<0.05)$ was detected, the Duncan Multiple Range Test was used to locate the source of difference. All statistical analyses including the descriptive statistics were computed using the SPSS 16 computer package.

\section{RESULTS}

Table 1: Lipid Profile of Test and Control Subjects

\begin{tabular}{|c|c|c|c|c|c|}
\hline $\begin{array}{l}\text { Parameter } \\
(\mathrm{mg} / \mathrm{dL})\end{array}$ & $\begin{array}{c}\text { Test group } 2 \\
\text { HAART: } \\
\text { 5-6 months }\end{array}$ & $\begin{array}{l}\text { Test group } 1 \\
\text { HAART: } \\
\text { 1-3 months }\end{array}$ & $\begin{array}{l}\text { Control Group } \\
1 \text { No HAART: } \\
\text { HIV positive }\end{array}$ & $\begin{array}{l}\text { Control Group } 2 \\
\text { No HAART: } \\
\text { HIV negative }\end{array}$ & P-value \\
\hline $\begin{array}{l}\text { Total } \\
\text { Cholesterol }\end{array}$ & $214.0^{A} \pm 6.43$ & $202.4^{A} \pm 5.09$ & $159.3^{B} \pm 5.09$ & $101.6^{c} \pm 3.76$ & $\begin{array}{l}P<0.001 \\
\text { Significant }\end{array}$ \\
\hline Triglyceride & $106.6^{A}+11.95$ & $135.8^{A}+9.88$ & $125.1^{\mathrm{B}} \pm 3.35$ & $104.6^{c} \pm 3.08$ & $\begin{array}{l}P<0.005 \\
\text { Significant }\end{array}$ \\
\hline HDL & $48.7^{A} \pm 3.95$ & $42.2^{B}+3.21$ & $39.6^{B} \pm 3.10$ & $25.1^{c} \pm 0.77$ & $\begin{array}{l}P<0.001 \\
\text { Significant }\end{array}$ \\
\hline LDL & $130.3^{A} \pm 6.36$ & $115.7^{B}+4.73$ & $106.5^{\mathrm{B}} \pm 3.12$ & $115.3^{B} \pm 1.54$ & $\begin{array}{l}P<0.005 \\
\text { Significant }\end{array}$ \\
\hline
\end{tabular}


Total cholesterol concentration of Test group $2(214 \pm 6.43 \mathrm{mg} / \mathrm{dL})$ was higher than the concentration obtained for Test group 1 (202 $\pm 5.09 \mathrm{mg} / \mathrm{dL})$, but the difference was not significant. These values were higher than values obtained for both control groups and the differences were highly statistically significant $(P<0.01)$. In the control groups, the total cholesterol concentration was higher in the control groups 1; HIV positive NO HAART; (159.3 $\pm 5.09 \mathrm{mg} / \mathrm{dL})$ than in control group 2, $(101.0 \pm 3.76 \mathrm{mg} / \mathrm{dL})$ and the difference was highly significant $(P<0.001)$. Table 1 also shows triglycerides concentrations of test and control groups. Pattern similar to the above (for cholesterol) was observed for triglyceride, however, differences observed were significant $(P<0.05)$.

As shown in table 1, HDL cholesterol concentration for test groups 2 (48.7 \pm 3.95 $\mathrm{mg} / \mathrm{dL}$ ) was higher than concentration of test group $1(42.2 \pm 3.21 \mathrm{mg} / \mathrm{dL})$ and the difference was highly significant $(P<0.001)$. There was however no significant difference between concentration of test group 1 and control group $1(39.6 \pm 3.10 \mathrm{mg} / \mathrm{dL})$. Comparison of $\mathrm{HDL}$ concentration between control groups showed that values obtained for control group 1 was higher than control group 2 (25.1 \pm 0.077 $\mathrm{mg} / \mathrm{dL}$ ) and the difference was highly significant $(P<001)$. Difference in LDL concentration between test group 2 (130.3 \pm $6.36 \mathrm{mg} / \mathrm{dL}$ ) and test group 1 (115.7 \pm 4.72 $\mathrm{mg} / \mathrm{dL})$ was significant $(p<0.05)$ though $\mathrm{LDL}$ concentration of test group was higher. It was however observed that there was no significant difference between LDL values obtained for test group 1 and the control group.

Table 2: Prevalence of Hypercholesterolaemia in the Different Subjects

\begin{tabular}{lllll}
\hline Total Cholesterol $(\mathrm{mg} / \mathrm{dL})$ & $\begin{array}{l}\text { HAART: } \\
1-3\end{array}$ & $\begin{array}{l}\text { HAART:5-6 } \\
\text { Months }\end{array}$ & $\begin{array}{l}\text { NO HAART: } \\
\text { HTV Positive }\end{array}$ & $\begin{array}{l}\text { NO HAART: } \\
\text { HIV } \\
\text { Negative }\end{array}$ \\
\hline Desirable $(<200 \mathrm{mg} / \mathrm{dL})$ & $44.90 \%$ & $36.60 \%$ & $100 \%$ & $90.20 \%$ \\
Borderline high $(200-239 \mathrm{mg} / \mathrm{dL})$ & $35.90 \%$ & $32.40 \%$ & $0.00 \%$ & $8.20 \%$ \\
High: $>240 \mathrm{mg} / \mathrm{dL}$ & $19.20 \%$ & $31.00 \%$ & $0.00 \%$ & $1.60 \%$ \\
\hline
\end{tabular}

Table 3: Prevalence of Hypertriglyceridaemia in the Different Subjects

\begin{tabular}{lllll}
\hline $\begin{array}{l}\text { Triglyceride } \\
\text { (mg/dL) }\end{array}$ & $\begin{array}{l}\text { HAART: 1 -3 } \\
\text { months }\end{array}$ & $\begin{array}{l}\text { HAART: 5-6 } \\
\text { months }\end{array}$ & $\begin{array}{l}\text { No HAART: HIV } \\
\text { Positive }\end{array}$ & $\begin{array}{l}\text { No HAART: } \\
\text { HIV Negative }\end{array}$ \\
\hline $\begin{array}{l}\text { Normal: } \\
<150\end{array}$ & $66.70 \%$ & $60.60 \%$ & $98.00 \%$ & $80.30 \%$ \\
$\begin{array}{l}\text { Borderline } \\
\text { High: }\end{array}$ & $15.40 \%$ & $8.40 \%$ & $2.00 \%$ & $19.70 \%$ \\
$\begin{array}{l}150-199 \\
\text { High: }\end{array}$ & $17.90 \%$ & $31.00 \%$ & & \\
$\begin{array}{l}200-499 \\
\text { Very High: }\end{array}$ & $0.00 \%$ & $0.00 \%$ & $0.00 \%$ & $0.00 \%$ \\
$>500$ & & $0.00 \%$ & $0.00 \%$ \\
\hline
\end{tabular}


Table 2 shows the prevalence of hypercholesterolemia in different groups of subjects under study. Control group 1 showed no incidence of either high or border line high cholesterol values. However, control group 2 (HIV negative, No HAART) $8.2 \%$ and $1.6 \%$ of subjects had border line high and high cholesterol values respectively. In the test groups the percentage of borderline high cholesterol level for test group 1 (35.9\%) was greater than the percentage of group 2 (32.4\%). However, high cholesterol (> $240 \mathrm{mg} / \mathrm{dl}$ ) was more prevalent in test group $2(31.0 \%)$ than in test group $1(19.2 \%)$. Summarily, values in table 15 shows that hypercholesterolemia (cholesterol $>200 \mathrm{mg} / \mathrm{dl}$ ) was more prevalent in test groups (HAART usage) than in control groups (no HAART).

Table 3 shows percentage of Hypertriglyceridaemia in test and control groups. Cases of Hypertriglyceridaemia (triglyceride greater than $150 \mathrm{mg} / \mathrm{dl}$ ) were observed in test group $1(15.4 \%$ and $17.9 \%)$ for border line high and high respectively; and $8.4 \%$ (Border line high) and 31.0\% (high) for test group 2. Incidence of high Hypertriglyceridaemia in test group $2(31 \%)$ was greater than $17.9 \%$ obtained for test group 1. There was no case of very high triglyceride (> 500mg/dl) in both test groups and control groups.

Table 4: Serum Lipids Concentration for Male and Female of Test Group 2

\begin{tabular}{llll}
\hline Parameter $(\mathrm{mg} / \mathrm{dL})$ & $\begin{array}{l}\text { Male 5-6 } \\
\text { Months }\end{array}$ & $\begin{array}{l}\text { Female 5-6 } \\
\text { Months }\end{array}$ & P-Value \\
\hline Total cholesterol & $212.2 \pm 9.21$ & $215.4 \pm 8.96$ & $\mathrm{P}>0.05$ \\
Triglycerides & $173.7 \pm 20.17$ & $151.0 \pm 14.54$ & $\mathrm{P}>0.05$ \\
\hline
\end{tabular}

Table 5: Mean Serum Lipids Concentration for Male and Female of Test Group 1

\begin{tabular}{llll}
\hline Parameter $(\mathrm{mg} / \mathrm{dL})$ & Male 1-3 Months & $\begin{array}{l}\text { Female 1-3 } \\
\text { Months }\end{array}$ & P-Value \\
\hline Total cholesterol & $186.6 \pm 9.33$ & $211.7 \pm 5.58$ & $P<0.05$ \\
Triglycerides & $163.2+20.29$ & $119.5+9.6$ & $P<0.05$ \\
\hline
\end{tabular}

Table 6: Mean Serum Lipid Concentration for Male and Female of Control Group 1

\begin{tabular}{llll}
\hline Parameter $(\mathrm{mg} / \mathrm{dL})$ & $\begin{array}{l}\text { Male 1-3 } \\
\text { Months }\end{array}$ & $\begin{array}{l}\text { Female 1-3 } \\
\text { Months }\end{array}$ & P-Value \\
\hline Total cholesterol & $98.85 \pm 5.33$ & $104.5 \pm 5.35$ & $\mathrm{P}>0.05$ \\
Triglycerides & $102.96 \pm 4.77$ & $106.33 \pm 3.88$ & $\mathrm{P}>0.05$ \\
\hline
\end{tabular}

Table 7: Mean Serum Lipid Concentration for Male and Female of Control Group 2

\begin{tabular}{llll}
\hline $\begin{array}{l}\text { Parameter } \\
(\mathrm{mg} / \mathrm{dL})\end{array}$ & $\begin{array}{l}\text { Male 5-6 } \\
\text { Months }\end{array}$ & $\begin{array}{l}\text { Female 5-6 } \\
\text { Months }\end{array}$ & P-Value \\
\hline Total cholesterol & $162.5 \pm 8.66$ & $156.5 \pm 5.8$ & $\mathrm{P}>0.05$ \\
Triglycerides & $123.0 \pm 5.17$ & $127.0 \pm 4.39$ & $\mathrm{P}>0.05$ \\
\hline
\end{tabular}

\section{DISCUSSION}

It would be clinically valuable for HIV

Chemotherapy to have minimal of negligible side effects with long-term use, alongside its effectiveness. The possible lipid derangement effects of the HAART used by participants in this study is of interest. The combination of the three different antiretroviral drugs made up of Nucleoside reverse transcriptase inhibitors (Stavudine and Lamivudine) and non- 
nucleoside reverse transcriptase inhibitors (nevirapine) used by participants in test groups 1 and 2 may be associated with has the considerable difference in their lipid profile indices, which obviously were higher compared with the control groups.

It could therefore be implied that the observed differences in serum lipid levels, (cholesterol for instance) in test groups (those with HAART usage) may be attributed to the influence of HAART on lipids metabolism. In this study, this comparatively higher levels in serum lipids of participants with HAART usage is being further supported by the percentage prevalence of hypercholesterolemia in test subjects which were significantly higher than prevalence seen in control subjects.

The non-usage of HAART by control subjects justifies the zero incidence and very low incidence of hypercholesterolemia in control group 1 and 2 respectively as indicated in tables 2 and 3 . Also, $8.4 \%$ borderline high and $31.0 \%$ high Hypertriglyceridaemia were seen in test group 2. This incidence of high Hypertriglyceridaemia ( $31 \%$ of subjects) in test group 2 was greater than the $17.9 \%$ obtained for test group 1. It could be implied that as the duration of HAART usage increases, the tendency for serious derangement in lipids like triglycerides is established. Changes in lipid levels (triglycerides) may be mild in short durations of HAART usage and this may have accounted for reason why there was no case of very high triglyceride (values $>500 \mathrm{mg} / \mathrm{dl}$ ) in the test groups, since HAART was used for short durations.

HAART usage has been linked to such metabolic disorders as dyslipidaemia, lipodystrophy, hyperinsulinaemia, hypoglycaemia, insulin resistance and lactic acidosis among others. Nucleoside analogue antiretroviral agents (NRTIs) exert their effect on HIV by inhibiting reverse transcriptase. These agents also inhibit mitochondrial DNA (mtDNA) polymerase in cell culture (Aggarwal et al., 1996; Aggarwal and Olivero, 1997); Pol et al., 2011). Inhibition of mtDNA can lead to a variety of metabolic abnormalities which include derangement in pyruvate metabolism and ultimately disorders in lipid profiles. Insulin resistance and hyperinsulinaemia are important metabolic disorders in HAART usage that lead to increased serum lipids. Insulin resistance in fat cells results in hydrolysis of stored triglycerides, which elevate free fatty acids in the blood plasma 4 . Subjects who are insulin resistant typically have an imbalance in their blood lipids ("blood fat). They have an increased level of triglycerides and a decreased level of HDL I good) cholesterol. Imbalances in triglycerides and HDL cholesterol increase the risk for heart disease ${ }^{5}$. Elevated serum triglycerides, total cholesterol and very low - density lipoproprotein (VLDL) cholesterol, and low density lipoprotein (LDL) cholesterol have been reported in literature from areas where experience with antiretroviral drugs has built up (Kubeyinje and Imarhiagbe, 2005). It was reported that $L D L$ cholesterol is one of the lipid parameters seriously affected by long duration HAART usage. Also, Riddler et al (2003) observed that before treatment, infection resulted in substantial decreases in serum total cholesterol, HDL and LDL cholesterol levels and that subsequent HAART initiation was associated increases in total cholesterol and LDL - cholesterol, but little change in HDL cholesterol.

In this study, as indicated in table 1 , difference in LDL concentration between test group 2 and test group 1 was significant; test group 2 was significantly higher than test group 1. When LDL concentration of test group 1 was compared with the control groups, though higher, the differences were not significant. Rising levels of LDL cholesterol in HIV subjects with HAART constitutes additional risk factor for heart related diseases like atherosclerosis and heart attack. The HAART group of 5-6 months (Test group 2) had higher HDL concentration than the 1-3 month HAART subjects (test group 1). This observation significantly varies with report of most studies which show decreasing levels of 
the beneficial cholesterol (HDL). HDL cholesterol has heart-protecting effect. The risk of HAART usage would have been significantly reduced if it were associated with rising levels of serum HDL cholesterol.

The values obtained in the study for total cholesterol, triglyceride and LDL cholesterol indicates that mild elevations are associated with HAART usage even for durations as short as $1-3$ months and 5 6 months. This is in line with the observations of Kubeyinge and Imarhiagbe in a locally conducted study (Kubeyinje and Imarhiagbe, 2005), who reported that 3 cases out of eleven followed up on antiretroviral drugs for a period of 6months had a steady rise in serum triglycerides among other parameters.

\section{Mitochondrial dysfunction which ultimately leads to gluconeogenesis, hyperinsulinaemia, insulin resistance, increased fat synthesis as well as, fatty liver development and weight gain are biochemical abnormalities that can directly alter liver enzymes and lipid profiles in HAART using HIV subjects. Occurrence of mitochondrial dysfunction is listed as part of the suggested mechanisms by which HAARTs cause cytotoxicities, (Stacpoole, et al., 1993; Aggarwal et al., 1997; Stacpoole et al., 1997; Ammassari et al., 2001). In mitochondrial toxicity, the mitochondria are damaged and lactic acid is not broken down. This can cause levels of lactic acid to become elevated. If this level becomes too high, a rare serious condition called lactic acidosis can occur.}

Lactic acidosis can result in liver problems, including a buildup of fat in and around the liver and liver inflammation (Parker and Cheng, 1994; Lewis et al., 1996; Aggarwal and Olivero, 1997; Ammassari et al., 2001). Suggested mechanisms and manifestations of mitochondrial dysfunction with HAART usage has been reported. The nucleoside analogue antiretroviral agents (stavudine and lamivudine used in this study) exert their effect on HIV by inhibiting reverse transcriptase. These agents also inhibit mitochondrial DNA (mtDNA) polymerase in cell culture (Aggarwal and Olivero, 1997; Riddler et al., 2001). The NRTIs have effect on mtDNA synthesis.

Inhibition of mtDNA can lead to a variety of metabolic abnormalities. These are largely the result of a derangement in pyruvate metabolism. After formation by glycolysis, pyruvate is metabolized in the mitochondria by pyruvate dehydrogenase (PDH) to acetyl coenzyme A (co A). Pyruvate may be reduced to lactate by lactate dehydrogenase, and it may also be used in gluconeogenesis (Stacpoole 1993; Stacpoole, 1997).

Inhibition of mtDNA causes a disorder of oxidative phosphorylation by making the mitochondrial respiratory chain dysfunctional and unable to break down acetyl CoA. This dysfunction shifts pyruvate metabolism forward the other pathways, reduction to lactate and gluconeogenesis. The lactate cannot be cleared as rapidly as it is being produced, and the resultant excess causes acidosis. The increase of pyruvate leads to increased gluconeogenesis in the liver, resulting in secondary diabetes mellitus (Kraise and Musher 1997). The gluconeogenesis stimulates insulin production. The over production of acetyl CoA without utilization in the respiratory chain pushes it out of the mitochondria to the cytoplasm, where it serves as a substrate for fat production. The over production of lactate causes lactic acidosis; the gluconeogenesis causes secondary diabetes mellitus and hyperinsulinaemia. Hyperinsulinaemia causes insulin resistance, and fat synthesis causes fatty liver and weight gain (Aggarwal and Olivero, 1997). Lactic acidosis which is as a result of mitochondrial toxicity as seen in the above mechanism can result to liver problems, including a build-up of fat in and around the liver and liver inflammation as well as increase fat synthesis (Qagish et al., 2000).

\section{CONCLUSION}

This study concludes that though there was no extreme cases of lipid derangement associated with the duration of HAART usage 
in the participants studied, the significant differences observed in lipid levels between study participants (test and control groups) show a trend in that direction. Serum lipids should therefore be evaluated before commencement of HAART and monitored in the course of HAART usage, possibly from the month of commencement.

\section{REFERENCES}

Aggarwal, A., al-Talib, K. and Alabrash, M. (1996).Type B lactic acidosis in an AIDS patient treated with zidovudine. Maryland State Medical Journal, 45: 929-931.

Aggarwal, R. P. and Olivero, O. A. (1997). Genotoxicity and mitochondrial damage in human lymphocytic cells chronically exposed to 3 '-azido-2', 3'dide-oxythymidine. Mutation Research, 390: 223-231.

Ammassari, A., Murri, R., Pezzott, P., Trotta, M., Ravasio, L., Delongis, P., Caputo, S., Narciso, P., Pauluzzi, S., Carosi, G., Nappa, S. and Antinori, A. (2001). The AIDS Pandemic: side effects of HAART. Journal of Acquired Immune Deficiency Syndromes; 28(5): 445-449.

Bakari, A. G. and Onyemelukwe, G. C. (2009) Insulin Resistance and Blood Pressure in Nigerian Type 2 diabetic patients. International Journal of Medicine and Medical Sciences, 4: 123-134.

Kubeyinje, E..P. and Imarhiagbe, F. A. (2005). Hypertriglyceridaemia in Antiretroviral Therapy. Medscape General Medicine, 7(3): 65.

Lewis, W., Levine, E. S. and Griniuviene, B. (1996). Fialuridine and its metabolites inhibit DNA polymerase gamma at sites of multiple adjacent analog incorporation, decrease mtDNA abundance, and cause mitochondrial structural defects in cultured hepatoblasts. Proceedings of the National Academy of Sciences; 93: 3592-3597.

Parker, W. B. and Cheng, Y. C. (1994). Mitochondrial toxicity of antiviral nucleoside analogs. The Journal of NIH Research, 6: 57-61.

Pol, S., Lebra, P. and Vallet, P. A. (2011). HIV infection and Hepatic Enzyme Abnormalities intricalies of the pathogenic Mechanisms. Clinical Infectious Diseases, 52(11): 65-72.

Riddler, S. A., Smit, E., Cole, S. R., Chmiel, J. S., Dobs, A., Pelella, F., Visscher, B., Evans, R. and Kingsley, L. A. (2003). Impart of HIV infection and HAART on serum Lipids in Men Journal of American Medical Association, 289(22): 2978-2982.

Stacpoole, P. W. (1993) Lactic acidosis. Endocrinology and Metabolism Clinics of North America; 22: 221-245.

Stacpoole, P. W. (1997). Lactic acidosis and other mitochondrial disorders. Metabolism, 46: 306-321.

Visnegarwala, F., Krause, K. L. and Musher, D. M. (1997). Severe diabetes associated with protease inhibitor therapy. Annals of Internal Medicine; 127: 947.

Qaqish, R. B., Fisher, E., Rublein, J. and Wohl, D. A. (2000) HIV-associated Lipodystrophy syndrome. Pharmacotherapy; 20: 13-22. 